\title{
Factum de la razón y conciencia moral Acerca de la normatividad en la moral kantiana
}

\author{
Miguel GONZÁLEZ VALLEJOS \\ Universidad Alberto Hurtado (Chile) \\ mgonzalv@uc.cl
}

\begin{abstract}
Resumen
La tesis central de este artículo sostiene que la doctrina del factum de la razón planteada en la Crítica de la razón práctica es insuficiente para dar cuenta de la normatividad de las leyes prácticas y que debe buscarse, por lo tanto, una evidencia directa de la "presión normativa» que las leyes morales ejercen sobre nosotros. Esta evidencia puede ser encontrada, de acuerdo a la tesis del autor, en la fenomenología de la conciencia que Kant desarrolla en la Doctrina de la Virtud, segunda parte de la Metafísica de las Costumbres.

Palabras claves: Kant, filosofía moral, conciencia moral, factum de la razón, imperativo categórico.

\section{Factum of the reason and moral consciousness About normativness in Kantian moral}

\begin{abstract}
The purpose of this article is to argue that the Kant's factum of reason doctrine raised in his work the Critique of Practical Reason it is insufficient to explain the normative role of the practical law and, for this reason, it is necessary to search for a direct evidence of the «normative pressure» practices must be sought, therefore, that moral laws have on us. This evidence can be found, according to the thesis on this article, on the phenomenology of consciousness developed by Kant in the Doctrine of Virtue, Part II of the Metaphysics of Morals.
\end{abstract}

Key words: Kant, moral philosophy, moral conscience, factum of reason, a categorical imperative, normative, practical law, phenomenology of consciousness.

Abogado y Licenciado en Filosofía (Pontificia Universidad Católica de Chile). Doctor en Filosofía (Konstanz Universität, Alemania). Profesor de Ética, Antropología Filosófica y Filosofía del Derecho en la Pontificia Universidad Católica de Chile. Profesor de Filosofía Moderna y Contemporánea en la Universidad Alberto Hurtado. Entre sus publicaciones cabe mencionar "El concepto de leyes prácticas en la ética kantiana" (2010). 


\section{Introducción}

¿Cuál es el principio moral fundamental? Kant sostiene en la Fundamentación para una metafísica de las costumbres (Grundlegung zur Metaphysik der Sitten) que este principio es el «imperativo categórico», cuya primera formulación, de acuerdo a la versión propuesta en la Crítica de la razón práctica (Kritik der praktischen Vernunft), dice: «Obra de tal modo que la máxima de tu voluntad siempre pueda valer al mismo tiempo como principio de una legislación universal» (Kant, 2002b; Ak. V. 3010). La realidad de esta ley moral en nuestra conciencia es, de acuerdo a Kant, un factum, es decir, un becho de la razón que no admite explicación ulterior. Si reconstruimos el razonamiento que nos permite formular las leyes morales, como por ejemplo, «no se debe matar» o «no se debe mentir», nos encontraremos necesariamente con el imperativo categórico, así como si estando en Valparaíso caminamos hacia el poniente nos encontraremos necesariamente con el mar $^{2}$.

La doctrina del factum de la razón es, sin embargo, y como veremos más adelante, insuficiente para dar cuenta del problema de la normatividad de las normas morales. Una norma, así Peter Stemmer, «ejerce una presión normativa (Handlungsdruck) y nos obliga a comportarnos de una determinada manera. En esto consiste su normatividad» (Stemmer, 2009: 59). Stemmer sostiene contra Kant que las normas morales formuladas de acuerdo al imperativo categórico («no matan», «no mentir», etc.) carecerían de normatividad. Esta objeción descansa en el siguiente razonamiento: (a) lo que constituye la normatividad de las normas morales son las sanciones morales (por

1 En adelante cito la obra de Kant según la traducción y la Akademie Ausgabe (Ak.).

2 La aceptación del imperativo categórico como principio fundamental de la moralidad y como factum de la razón tiene importantes consecuencias en el ámbito de la ética normativa. Una de las consecuencias más relevantes consiste en la imposibilidad de todo desacuerdo grave en materia moral. En efecto, dada la existencia de un solo principio moral con varias formulaciones y de una sola manera de razonar moralmente, esto es a través de la aplicación de dichas formulaciones del imperativo categórico a las máximas de las acciones, la consecuencia necesaria es que diferentes personas llegarán a similares conclusiones cuando razonen moralmente. De esta manera, y siguiendo el razonamiento de Kant, es posible formular un catálogo de deberes para consigo mismo y para con los demás cuya validez es universal y que no admite contradicción alguna, ya que habría una «armonía prestablecida» de deberes morales (cfr. Kant, 2002c; Ak. VI. 224). La raíz del error moral radica, de acuerdo a Kant, en que el sujeto moral, a pesar de conocer la ley moral, decide hacer una excepción a favor de sí mismo a favor de las inclinaciones, es decir, a favor de intereses o deseos subjetivos. Quién miente, piensa Kant, no desconoce que hay una ley moral que prohíbe mentir, sino que decide hacer una excepción a la regla. Una excepción que desde la perspectiva de Kant resulta siempre injustificada y, por lo tanto, inmoral (cfr. Kant, 2002a; Ak. IV. 424). 
ejemplo, el rechazo o la expulsión del grupo social); (b) una norma moral que no esté asociada a una sanción no sería una verdadera norma («no se debe mentir») y caería en la categoría de consejo («sería bueno que no mintieras»); (c) «las leyes prácticas» de Kant no están asociadas a sanciones. Por lo tanto, las leyes prácticas no son auténticas leyes morales. De acuerdo al contractualismo en general, y a Stemmer en particular, las auténticas normas morales no serían imperativos categóricos, es decir, normas morales absolutas o incondicionadas, sino imperativos hipotéticos. La norma que manda «no mentir» debería ser formulada de la siguiente manera: «si quieres evitar la sanción moral X, no debes mentir».

La discusión acerca de la normatividad de las leyes prácticas parece transformarse en este punto en un diálogo de sordos. Los kantianos afirman que hay un factum de la razón y que hay leyes morales absolutas, esto es, leyes morales que no dependen de ningún querer fáctico. La obligatoriedad de las normas morales, así Kant y sus discípulos, no depende ni de la existencia de sanciones ni del querer evitarlas ${ }^{3}$. Los autores contractualistas, por el contrario, niegan la existencia tanto del factum de la razón expuesto por Kant en la Crítica de la rąón práctica, así como de «imperativos categóricos», esto es, de leyes morales absolutas o incondicionadas sin sanciones. ¿Cómo salir de este diálogo de sordos? $¿$ Hay razones que permitan afirmar la normatividad de las leyes morales sin recurrir a las sanciones? La respuesta a la pregunta por la normatividad de las leyes prácticas la encontramos en la doctrina de la conciencia moral que Kant desarrolla en la «Doctrina de la virtud» (Tugendlebre), publicada como la segunda parte de la Metafísica de las

3 En el Prólogo a la Fundamentación señala Kant lo siguiente: «Cualquiera ha de reconocer que una ley, cuando debe valer moralmente, o sea, como fundamento de una obligación, tendría que conllevar una necesidad absoluta...» (Kant 2002a; Ak. IV. 388). Con la expresión «necesidad absoluta» Kant se refiere al hecho de que una norma moral, para ser tal, no puede estar sujeta a condición alguna. Una ley moral que prohíba mentir no puede, en consecuencia, ser formulada en términos hipotéticos («si no quieres tener problemas, nunca debes mentir»), sino en términos absolutos $\mathrm{O}$ categóricos («no debes mentir». Punto). La categoricidad de las normas morales está además en conexión interna con la autonomía moral. Si las normas morales encontraran su origen último en Dios (moral teonómica) o en un contrato hipotético (moral contractualista), tendrían ellas entonces una estructura hipotética (si quieres evitar las sanciones, debes hacer/omitir X) y no serían auténticas normas morales. Si las normas morales, en cambio, vinieran de la razón, entonces todos los seres racionales tendrían una razón interna para obedecerlas, ya que todo ser racional puede afirmar que las leyes morales son sus leyes. El error de todos los sistemas morales anteriores a Kant, como el mismo lo señala, radica precisamente en no haber tomado en cuenta el concepto de autonomía (cfr. Kant 2002a; Ak. IV. 432). Para un tratamiento detallado de este problema y del concepto de leyes prácticas en general, cfr. González Vallejos 2010 y 2012. 
costumbres (Metaphysik der Sitten), cuyos antecedentes se remontan también a las Lecciones de filosofía moral (Vorlesungen zur Moralphilosophie) que Kant dictó durante varios años en la Universidad de Könisberg. Lo que Kant hace en estos textos, más que una teoría, es una fenomenología de la conciencia moral. Se trata, como veremos a continuación, de una constatación fenomenológica de la realidad de la conciencia moral y del carácter absoluto de sus mandatos. Una adecuada comprensión del fenómeno de la conciencia moral permite dirimir el conflicto entre Kant y el contractualismo a favor de Kant. Para desarrollar la presente tesis, analizaré a continuación el contexto en el que se desarrolla el problema de la normatividad de las leyes prácticas, tomando en cuenta especialmente la doctrina del factum de la razón y luego la concepción de conciencia moral en Kant, para después exponer mis conclusiones.

\section{El problema de la normatividad de las leyes morales en el contexto de la filosofía moral kantiana}

En la Fundamentación para una metafísica de las costumbres desarrolla Kant la pregunta por el principio fundamental de la moralidad. En el capítulo II de esta obra presenta las diversas formulaciones de este principio, entre las que destacan la «Fórmula de Universalidad» (Kant, 2002a; Ak. IV. 421) y la «Fórmula de Humanidad» (Kant, 2002a; Ak. IV. 429-430). En el capítulo III intenta Kant solucionar el problema de la obligatoriedad de las leyes morales recurriendo a la teoría de los dos mundos. A partir de la primacía del «mundo inteligible» por sobre el «mundo sensible» concluye Kant la obligatoriedad de las leyes prácticas por sobre las leyes de la naturaleza ${ }^{4}$. Hay consenso en la literatura especializada en que la deducción de la obligatoriedad de la leyes morales intentada por Kant en Fundamentación III falla ${ }^{5}$. Así parece también haberlo entendido Kant, quien propone en la Crítica de la razón práctica una respuesta alternativa al problema. Dicha respuesta es la doctrina del factum de la razón. Para entender esta doctrina debemos primero aclarar algunos problemas fundamentales relativos a la segunda crítica.

La tarea que otorga sentido a la reflexión que hace Kant en la Crítica de la razón práctica consiste en averiguar «si la razón pura se basta por sí sola para determinar a la voluntad o si sólo en cuanto que la razón se

4 Para un comentario de Grundlegung III, cfr. Schönecker \& Wood, 2002; González Vallejos, 2012: 96-116.

5 Cfr. Henrich, 1998: 312-318; Korsgaard, 1996: 170; Schönecker \& Wood, 2002: 195ss. 
halle empíricamente condicionada puede oficiar como un fundamento para determinar dicha voluntad» (Kant, 2002b; Ak. V. 15). En otras palabras, Kant busca dar cuenta de la posibilidad de la autonomía moral. ¿Qué entendemos por autonomía moral? La autonomía, dice Kant, es «una modalidad de la voluntad, en virtud de la cual ella es una ley para sí misma, independientemente de toda modalidad del objeto de la voluntad» (Kant, 2002a; Ak. IV. 440) ${ }^{6}$. Kant identifica en Fundamentación II, voluntad y razón práctica. El punto central del concepto de autonomía radica en lo siguiente: el origen de los deberes morales es nuestra razón. El imperativo categórico es un principio a priori de la razón práctica, es decir, un principio anterior a toda experiencia que da cuenta del origen de las leyes morales. Sólo porque las leyes morales son reglas $a$ priori puede afirmar Kant que la fidelidad es exigible en la amistad, aun cuando nunca hubiera existido un amigo leal. No es que Kant observe como de hecho se comportan los amigos, sino que asumiendo que hay leyes morales absolutas y universales, como por ejemplo «no se debe mentir» (Kant, 2002a; Ak. IV. 387), busca el origen de estas leyes y las encuentra en el imperativo categórico.

Decíamos que el problema de la Crítica de la razón práctica consiste, tal como ocurre en la Fundamentación III, en dar cuenta de la autonomía moral. Kant ve al hombre sometido a dos legislaciones. Las leyes de la naturaleza (Naturgesetze) son leyes «según las cuales todo sucede» (Kant, 2002a; Ak. IV. 388). Kant piensa que el hombre en cuanto ser natural está sometido a estas leyes. Todas nuestras inclinaciones, es decir, nuestros deseos e intereses subjetivos, y nuestro deseo de felicidad, al cual apuntan finalmente todas las inclinaciones, son explicados por Kant a través de las leyes de la naturaleza. A las leyes de la naturaleza se contraponen las leyes prácticas (praktische Gesetze), leyes «según las cuales todo debe suceder» (Kant, 2002a; Ak. IV. 388), que se identifican con lo que hoy conocemos como normas morales absolutas, por ejemplo, la prohibición del suicidio y de la mentira y la ley moral que nos manda

\footnotetext{
6 Con el concepto de autonomía pretende Kant dar cuenta del origen y de la legitimidad de las leyes morales. Ellas no son, como afirmaba Grocio, leyes de la razón respaldadas por la autoridad divina, ni mucho menos leyes naturales que reflejan la voluntad de Dios, como pensaba Pufendorf. Tampoco son leyes que puedan ser explicadas con el recurso al contrato social, como sostenían Hobbes y Locke. Se trata de nuestras leyes. En cuanto somos seres racionales, piensa Kant, nos damos leyes morales a nosotros mismos. El origen y la legitimidad de ellas descansan en su origen en nuestra razón. El paso desde la legislación divina respaldada por sanciones a la autolegislación moral sin sanciones es lo que he denominado en un trabajo anterior el giro kantiano en el concepto de leyes prácticas en el pensamiento de Kant (Die Wende im Begriff der praktischen Gesetze bei Kant), González Vallejos, 2012.
} 
ayudar a los demás en caso de necesidad. Sólo las leyes prácticas tienen su origen en nuestra razón. El problema se plantea precisamente en el marco de los conflictos que suelen darse entre las leyes prácticas y nuestras inclinaciones. Un hombre con problemas económicos, de acuerdo al clásico ejemplo de Kant, siente el impulso de hacer una falsa promesa de pago para obtener un préstamo. Frente a este impulso, que responde a un deseo de felicidad, que a su vez es explicado por las leyes de la naturaleza, hay una ley práctica que prohíbe la mentira bajo cualquier circunstancia. Hay entonces un conflicto, y la pregunta es: ¿cómo sabemos que las leyes prácticas tienen prioridad por sobre las leyes de la naturaleza? ¿Cómo sabemos que hay autonomía moral, es decir, que nos damos leyes morales y que estas leyes son efectivamente obligatorias? La respuesta de Kant a esta pregunta en la Crítica de la razón práctica es la doctrina del factum de la razón que analizaremos a continuación.

\section{E1 factum de la razón}

En la Crítica de la razón práctica propone Kant la siguiente formulación del imperativo categórico: «Obra de tal modo que la máxima de tu voluntad siempre pueda valer al mismo tiempo como principio de una legislación universal» (Kant, 2002b; Ak. V. 30). Más adelante agrega: «La conciencia de esta ley básica puede verse llamada "un factum de la razón", dado que no cabe inferirla de datos precedentes de la razón como por ejemplo la consciencia de la libertad (pues ésta no nos es dada con anterioridad), sino que se nos impone por sí misma como una proposición sintética a priori, la cual no se funda sobre intuición alguna, ni empírica ni pura, aun cuando sería analítica si se presupusiera la libertad de la voluntad, si bien para semejante concepto positivo sería requerida una intuición intelectual que no cabe admitir de modo alguno» (Kant, 2002b; Ak. V. 31). A través de este único factum de la razón práctica, el cual Kant considera «innegable» (Kant, 2002b; Ak. V. 32), la razón se revela «como originariamente legisladora». Esto significa que a través del factum de la razón la obligatoriedad del principio de moralidad y de las leyes morales y la realidad de la autonomía moral son confirmadas. En este sentido dice el corolario de esta doctrina: «la razón pura es por sí sola práctica y proporciona (al ser humano) una ley universal que damos en llamar la ley moral) (Kant, 2002; Ak. V. 32).

Pero, ¿qué es el factum de la razón? Para esta pregunta encontramos una clara respuesta en Höffe, quien dice: «Con el factum de la razón se refiere Kant no a la ley moral misma, sino a la conciencia de ella. Se trata 
para Kant del hecho indiscutible y apodíctico, dado a priori y no por la experiencia, del estar conscientes de una obligación absoluta. En este hecho se revela la razón como "originalmente legisladora" (sic volo, sic jubeo)» (Höffe, 2002: 14). El factum no es una «intuición intelectual» del principio de moralidad, como señala expresamente Kant, ni tampoco significa que todas las personas sean capaces de formular expresamente el imperativo categórico. Con la palabra factum Kant se refiere a un hecho «con el cual la razón necesariamente choca» (Willaschek, 1992: 178). El factum consiste en nuestra conciencia de la ley moral, es decir, en nuestra conciencia del imperativo categórico. Kant ejemplifica esta conciencia de la ley moral a través del caso de un hombre que es conminado por la autoridad a dar un falso testimonio. Este hombre, piensa Kant, a pesar de su miedo a ser ejecutado, sabe que su deber es abstenerse de dar un falso testimonio contra un hombre honrado (Kant, 2002b; Ak V. 30). Que de hecho tengamos conciencia de la ley moral significa, en definitiva, que si reconstruimos nuestro razonamiento moral y buscamos las condiciones que lo hacen posible, nos encontraremos necesariamente con el imperativo categórico. Afirmar, por ejemplo, que hay una norma moral absoluta que prohíbe mentir, tendría como supuesto implícito que (1) la máxima «daré un falso testimonio contra un hombre honrado para evitar ser perjudicado o dañado» no puede ser querida como ley universal y al mismo tiempo que (2) mentir supone utilizar a otro sólo como un medio. De acuerdo a los planteamientos de Kant, todo razonamiento moral puede ser reconstruido como una aplicación del imperativo categórico a la máxima de la respectiva acción.

\section{Problemas filosóficos asociados al factum de la razón}

La reconstrucción que hace Kant de las normas morales resulta, sin embargo, problemática. En primer lugar, porque no es la única reconstrucción posible del razonamiento moral. Desde una perspectiva contractualista, por ejemplo, podría argumentarse que la prohibición de mentir puede ser explicada recurriendo a un contrato hipotético. En términos simples: porque nadie quiere ser engañado, la comunidad moral ha asociado la acción de mentir a una sanción moral, y sólo por eso es posible afirmar que hay una norma moral que prohíbe mentir. Así también podría explicarse la prohibición de mentir desde una perspectiva religiosa: la mentira puede considerarse como una falta contra el mandato de amor al prójimo, y por lo tanto, como un pecado. Una segunda objeción contra la reconstrucción kantiana del razonamiento moral -la objeción que atañe directamente al presente trabajo- apunta a 
la ausencia de normatividad de las leyes prácticas formuladas a través del imperativo categórico. Stemmer señala que para él resulta incomprensible que de un mero razonamiento - como sería lo dicho acerca del principio de moralidad- pueda nacer una norma moral (Stemmer, 2009: 59ss).

¿Cómo evaluar filosóficamente estas objeciones? Para contestarlas ¿basta con decir simplemente «yo veo que hay un imperativo categórico y que hay leyes morales absolutas»? Una respuesta así sería insuficiente por varias razones. En primer lugar, porque el mismo Kant aclara que el factum de la razón no es conocido a través de una intuición intelectual. En segundo lugar, porque contra esa afirmación viene inmediatamente una objeción obvia - «yo no veo ni que haya un imperativo categórico ni que haya leyes morales absolutas» $-\mathrm{y}$ la discusión filosófica se transforma entonces en un diálogo de sordos. ¿Cómo solucionar entonces este problema?

Si analizamos la ética de Kant desde una perspectiva sistemática, concluimos con claridad que la doctrina del factum de la razón no es por sí sola suficiente para dar cuenta de la normatividad de las leyes prácticas. El factum de la razón establece una primera tesis: tenemos conciencia de estar obligados por el principio de moralidad. Dicha conciencia se refiere por lo tanto al imperativo categórico en cuanto principio de moralidad y no a las leyes prácticas, es decir, no a las normas morales propiamente tales. Una alternativa que nos permitiría solucionar este problema sería argumentar que de la obligatoriedad del principio de moralidad se sigue necesariamente la normatividad de las normas morales. Esta respuesta es, sin embargo, insuficiente. La realidad de un factum de la razón puede ser puesta en duda y se enfrenta con muchas otras posibles reconstrucciones del razonamiento moral, en especial con la reconstrucción propuesta por el contractualismo. Pienso que para afirmar que las leyes prácticas tienen normatividad es necesaria una confirmación adicional. El problema que estamos enfrentando se asemeja a un proceso criminal. La presunta víctima afirma la existencia de un hecho, por ejemplo, «X me asaltó ayer y me quitó 20.000 pesos»; el acusado, en cambio, niega los hechos: «yo no fui quien asaltó ayer a la víctima. Fue una persona con rasgos parecidos a los míos, pero no fui yo. A esa hora estaba en mi casa junto a mi familia». En un caso así, el juez de la causa requerirá la presencia de testigos. En el caso que el hecho no sea un hecho delictual, sino un «hecho de la razón», ¿podremos contar con algún testigo? Yo sostengo en este trabajo que sí hay un testigo que puede dar testimonio directo de que hay leyes morales absolutas. Este testigo que favorece a Kant es la conciencia moral. El próximo paso de mi argumentación consiste, por lo tanto, en analizar la doctrina kantiana de la conciencia moral expuesta en 
la Crítica de la razón práctica y en la «Doctrina de la Virtud», luego analizar el rol mediador que Kant le atribuye a la conciencia moral y finalmente volver al problema de la normatividad.

\section{La conciencia moral}

\subsection{La conciencia moral (Gewissen) en la Crítica de la razón práctica}

$\mathrm{Ni}$ en la Fundamentación para una metafísica de las costumbres ni en la Crítica de la razón práctica encontramos un tratamiento sistemático de la conciencia moral. La razón de esto radica en que Kant pretende en estos textos sólo reflexionar en torno al primer principio de moralidad y no desarrollar la doctrina de la virtud como tal (i.e. desarrollar la moral material). Sin perjuicio de esto, encontramos en la Crítica de la razón práctica un texto que da cuenta de la importancia sistemática de la conciencia moral en la ética de Kant. Analizaré a continuación este pasaje para después dar cuenta del tratamiento de la conciencia moral que Kant realiza en la «Doctrina de la virtud».

En el capítulo titulado «Aclaración crítica a la Analítica de la razón pura práctica» señala Kant que el hombre en cuanto noúmeno tiene conciencia de su libertad. Respecto a toda acción contraria a la ley moral, el hombre que podría no haberla cometido y que ella puede ser imputada «a una causa independiente a toda sensibilidad» (Kant, 2002b; Ak. V. 98). A esto agrega:

Con esto coinciden también perfectamente las sentencias de aquella maravillosa capacidad que se halla en nuestro fuero interno y a la cual denominamos "conciencia moral". Un ser humano puede rebuscar cuanto quiera al evocar cierto comportamiento contrario a la ley, para escenificarlo como un desliz inintencionado, como una simple imprevisión de la que no cabe nunca sustraerse por completo y, en definitiva, cómo a lo cual se vio arrastrado por el torrente de la necesidad natural, declarándose inocente por todo ello. Sin embargo, descubre que aquel abogado defensor, al hablar a su favor, no puede hacer acallar de ningún modo a ese fiscal acusador ubicado en su fuero interno, si es consciente de que cuando perpetró esa injusticia se hallaba en sus cabales, o sea, en el uso de su libertad, y aun cuando se explique su falta por cierta mala costumbre contraída mediante un paulatino descuido sobre uno mismo, e incluso llegue hasta el extremo de poder verla como una consecuencia natural del proceso recién descrito, todo ello no puede ponerla a salvo de la autocensura y los reproches que se hace a sí mismo. En esto se funda 
también el arrepentimiento que suele acompañar al recuerdo de un acto cometido hace largo tiempo; se trata de una sensación dolorosa producida por la intención moral que resulta vana en términos prácticos, por cuanto dicha sensación no puede servir para deshacer lo hecho... (Kant, 2002b; Ak. V. 98).

En el citado pasaje de la Crítica de la razón práctica encontramos los elementos centrales del fenómeno de la conciencia moral que luego será descrito detalladamente en la «Doctrina de la Virtud». En primer lugar, encontramos el vínculo entre conciencia moral y libertad. A través de conciencia moral, así como a través del factum de la razón, tenemos conciencia de nuestra libertad. Cada acción realizada podría no haber tenido lugar, podría haber sido realizada de otra manera. Decimos habitualmente, por ejemplo: "podría haberme levantado antes y no hubiera llegado tarde», "podría haber sido más cuidadoso», "podría haberme informado mejon», etc. Resulta difícil atribuir nuestras malas acciones y descuidos a las leyes de la naturaleza (Naturgesetze). La conciencia moral da testimonio de la libertad. En segundo lugar, encontramos ya en este pasaje el vocabulario jurídico que Kant utilizará después para desarrollar su fenomenología de la conciencia. Kant se refiere aquí a un «abogado defensor» «que no puede hacer acallar de ningún modo a ese fiscal acusador ubicado en su fuero interno» (Kant, 2002b; Ak. V. 98) En tercer lugar, Kant establece una condición para que opere el juicio de la conciencia moral: el hombre debe ser consciente «de haber estado en sus cabales» en el momento en el que realizó el acto, es decir, haber estado en el uso de su libertad. Que el acto realizado pueda ser explicado por una mala costumbre no afecta al juicio de culpabilidad realizado por la conciencia. En cuarto lugar, al referirse Kant a las «sentencias» de la conciencia moral alude implícitamente al carácter mediador que juega la conciencia moral en relación a las leyes prácticas y las circunstancias concretas. Me referiré a continuación a este punto crucial.

Las leyes prácticas, así Kant en el prólogo a la Fundamentación, son universales (Kant, 2002a; Ak. IV. 389). La universalidad es pensada por Kant de acuerdo al modelo de las leyes de la naturaleza. De esta manera, las leyes prácticas son válidas para todo ser racional y no admiten la menor excepción. El error moral consiste precisamente en hacer excepciones a las leyes morales (Kant, 2002a; Ak. IV. 424). En este contexto, entonces, surge un grave problema: ¿cómo saltar el abismo que hay entre leyes prácticas de máxima generalidad, o bien, de máximas cuya universalidad debe poder ser querida, por un lado, y la infinita variedad de las circunstancias posibles, por otro? Kant ha visto este problema en 
toda su gravedad. En el opúsculo titulado En torno al tópico, tal vez eso sea correcto en teoría, pero no sirve para la práctica, señala:

Por muy completa que sea la teoría, salta a la vista que entre la teoría y la práctica se requiere aún un término medio como enlace para el tránsito de la una hacia la otra cosa, pues al concepto del entendimiento, concepto que contiene la regla, se tiene que añadir un acto de la facultad de juzgar por medio del cual el práctico distingue si algo cae bajo la regla o no. Y como, por otra parte, para la facultad de juzgar no siempre se pueden dar reglas conforme a las cuales tenga que regirse en la subsunción (porque se daría un regressus in infinitum), puede haber teóricos que nunca en su vida serán capaces de convertirse en prácticos, porque carecen de la facultad de juzgar; tal es el caso, por ejemplo, de médicos o juristas que han hecho bien sus estudios, pero no saben cómo han de conducirse a la hora de dar un consejo (Kant, 1986; Ak. 275).

A los ejemplos propuestos por Kant podemos legítimamente agregar el caso de quien toma decisiones morales. Si bien la facultad del juicio no parece tan relevante a la hora de aplicar el precepto moral «no mentir», es evidente que los deberes amplios o deberes de virtud (perfección propia y felicidad ajena) requieren necesariamente de su intervención, ya que «si la ley sólo puede ordenar la máxima de las acciones, no las acciones mismas, este es un signo de que deja un margen (latitudo) al arbitrio libre para el cumplimiento (la observancia), es decir, que no puede indicar con precisión cómo y cuánto se debe obrar con la acción con vistas al fin que a la vez es deber» (Kant, 2002c; Ak. VI. 390).

La consideración de los cuatro elementos señalados, cuyo análisis profundizaré en los próximos parágrafos, confirma el lugar central que la conciencia moral ocupa en la filosofía moral de Kant. La única razón por la cual la conciencia no es tratada a fondo ni en la Fundamentación ni en la Crítica de la razón práctica es que ambas obras se enfocan en determinar cuál es el principio moral fundamental y cómo este principio es determinante respecto a nuestras acciones, respectivamente.

\subsection{La conciencia moral en la «Doctrina de la virtud»}

La tesis de este trabajo puede ser así resumida: la normatividad de las leyes prácticas puede ser comprobada a través de una fenomenología de la conciencia. Para defender esta tesis analizaré a continuación los pasajes más relevantes relativos a la conciencia moral en la Doctrina de la virtud. Se trata de las «prenociones estéticas de la receptividad del ánimo para los conceptos del deber en general» (Kant, 2002c; Ak. VI 399-401) y del pasaje acerca «del deber del hombre hacia sí mismo, considerado como 
su propio juez innato» (Kant, 2002c; Ak. VI 399-401). Pienso que una consideración atenta de estos pasajes, unida a una adecuada interpretación, permitirá explicar dos aspectos fundamentales e interdependientes: el rol mediador y la fuerza normativa que Kant atribuye a la conciencia moral. Ambos aspectos están presentes en la metáfora del tribunal de la conciencia, imagen que analizaré en sus diversos aspectos.

A) La conciencia moral como una prenoción estética de la receptividad del ánimo para los conceptos del deber en general.

Con el adjetivo «estético» se refiere Kant al ámbito de los sentimientos. Con la palabra «prenoción»s se refiere a las condiciones de posibilidad de nuestra receptividad de los conceptos de deber. Se trata de disposiciones estéticas que todo hombre posee y que le permiten ser afectado por los conceptos del deber. No tiene que ver con el juicio moral propiamente tal. Son el sentimiento moral, la conciencia moral, el amor al prójimo y el respeto por sí mismo.

En el contexto de las prenociones estéticas encontramos una primera definición de conciencia moral. «Estar obligado a adquirir la conciencia moral -señala Kant- sería tanto como decir: tener el deber de reconocer deberes. Porque la conciencia moral es la razón práctica que muestra al hombre su deber en cada caso concreto de una ley, absolviéndolo o condenándolo» (Kant, 2002c; Ak. VI. 400). En esta definición encontramos que Kant identifica conciencia moral y razón práctica. Se trata claramente de una identificación con la razón práctica sólo en cuanto facultad del juicio, cuya función consiste en la aplicación de las leyes morales (cfr. Kant, 2007; Ak. V. 179). Un segundo aspecto relevante es que la conciencia moral no es en ningún caso autora de las leyes prácticas. La conciencia moral ordena reconocer los deberes morales que están contenidos en las leyes prácticas. Un tercer aspecto relevante radica en el rol que Kant le asigna a la conciencia moral: «absolver o condenar». Para entender adecuadamente este punto debemos considerarlo en el contexto de la fenomenología de la conciencia moral que Kant desarrolla a través de la metáfora del tribunal. Kant simboliza la conciencia moral con la imagen de un tribunal interior ante el cual debemos responder por nuestras acciones. Si nuestras acciones que están bajo sospecha de inmoralidad pueden ser adecuadamente justificadas, entonces nuestra conciencia nos absuelve. Si esta justificación no es posible, somos condenados. Volveré más tarde sobre este punto. Por ahora es necesario destacar un cuarto punto. De acuerdo a Kant, la conciencia moral es «un hecho inevitable» (Kant, 2002c; Ak. VI. 400). En otras palabras, la conciencia moral tiene un carácter originario. 
¿Cuáles son las consecuencias de atribuir a la conciencia moral un carácter originario? En primer lugar, que no hay un deber de tener conciencia moral (Kant, 2002c; Ak. VI. 400). En segundo lugar, que no es correcto decir «este hombre no tiene conciencia moral» (Ibíd.). Lo correcto sería decir, así Kant, es que este hombre «no tiene en cuenta» la sentencia de su conciencia moral (Ibíd.). Este punto es, sin duda, problemático en dos aspectos fundamentales: (a) ¿es razonable decir que los autores de graves delitos o los dictadores responsables de graves atentados contra civiles inocentes tienen conciencia moral, pero simplemente «no la tiene en cuenta»? ¿Cómo da cuenta Kant del fenómeno que nosotros conocemos como «falta de conciencia moral» (Gewissenlosigkeit)?; (b) ¿cómo explicar la conducta de quienes declarando «actuar en conciencia» cometen graves crímenes, como ocurre en el caso de los fanáticos religiosos? La primera pregunta puede ser respondida por medio de la descripción que Kant hace de la voz de la conciencia. El hombre, dice Kant, "puede ciertamente aturdirse o adormecerse con placeres y diversiones, pero no puede evitar volver en sí o despertar tan pronto oye su terrible voz. El hombre puede llegar en su extrema depravación hasta no hacerle ningún caso, pero, sin embargo, no puede dejar de oírla» (Ibíd.). De acuerdo a este pasaje no es posible «dejar de oír» la voz de la conciencia, pero sí es posible «no hacerle ningún caso». Concentrémonos ahora en responder la pregunta por el error al actuar en conciencia, es decir, el caso del fanático. Kant señala respecto a este problema lo siguiente: «una conciencia moral errónea es un absurdo. Porque muy bien podemos equivocarnos a veces en el juicio objetivo sobre si algo es o no deber, pero yo no puede equivocarme en el juicio subjetivo sobre si yo lo he comparado con mi razón práctica (que aquí juzga) para emitir aquel juicio, porque en tal caso no habría juzgado prácticamente en absoluto; en cuyo caso no hay ni error ni verdad» (Kant, 2002c; Ak. VI. 401). A partir de la lectura de este pasaje es claro que Kant entiende la idea de conciencia moral errónea de manera muy restringida. El término conciencia moral errónea alude al error consistente en equivocarnos al saber si de hecho hemos realizado un juicio de conciencia. Sostener que semejante error es posible, piensa Kant, sería absurdo. El error propiamente moral, sin embargo, es de otra naturaleza. Kant afirma que «muy bien podemos equivocarnos a veces en el juicio objetivo sobre si algo es o no deber» (Ibíd.). Y como para él el único método posible para conocer cuáles son nuestros deberes es la aplicación del imperativo categórico a las máximas de las acciones, entonces, bien puede decirse: «muy bien podemos equivocarnos en la aplicación del imperativo categórico». De acuerdo con esto es perfectamente plausible 
que un terrorista piense que la máxima de sus acciones violentas puede ser querida como ley universal (primera formulación).

B) La fenomenología de la conciencia moral en la Doctrina de la virtud: «el deber del hombre hacia sí mismo, considerado como su propio juez innato» (Kant, 2002c; Ak. VI. 437-440).

En la «Doctrina de la virtud» Kant distingue entre los deberes del hombre para consigo mismo y los deberes de virtud hacia los demás. Los deberes del hombre hacia sí mismo pueden ser perfectos o imperfectos. Dentro de los deberes del hombre hacia sí mismo perfectos encontramos «el deber del hombre hacia sí mismo, considerado como su propio juez innato». Al explicar este deber del hombre hacia sí mismo desarrolla Kant una fenomenología de la conciencia.

Como punto de partida, Kant diferencia entre «la coerción objetiva de la ley» (Kant, 2002c; Ak. VI. 437) que todo deber moral contiene, esto es, el mandato moral, y la «imputación interna» (Ibíd.) de una acción, en tanto ella constituye la aplicación de una ley moral. La imputación interna consiste en que la conciencia moral confronta al hombre con sus deberes morales. El resultado de esta confrontación es una condena o una absolución. El juicio, señala Kant, en cuanto principio subjetivo de la imputación de la acción, «juzga con fuerza legal si se ha realizado o no como acto (como acción que se encuentra bajo una ley); después de esto viene la conclusión de la razón (la sentencia), es decir, el enlace del efecto jurídico con la acción (la condena y la absolución): todo ello sucede ante una audiencia (coram indicio) llamada tribunal (forum), como persona moral que hace efectiva la ley» (Kant, 2002c; Ak. VI. 438). La conciencia moral es «la conciencia de un tribunal interno al hombre ante el cual sus pensamientos se acusan o se disculpan entre sí» (Ibíd.).

Todo hombre - así Kant- tiene conciencia moral y un juez interno le observa, le amenaza, le mantiene en el respeto (respeto unido al miedo), y este poder, que vela en él por las leyes, no es algo que él se forja (arbitrariamente), sino que está incorporado a su ser. Le sigue como su sombra cuando piensa escapar. Él puede ciertamente aturdirse o adormecerse con placeres y diversiones, pero no puede evitar volver en sí o despertar tan pronto oye su terrible voz. El hombre puede llegar en su extrema depravación hasta no hacerle ningún caso, pero, sin embargo, no puede dejar de oirla (Kant, 2002c; Ak. VI. 438).

La función judicial de la conciencia moral supone, piensa Kant además, que en virtud de ella el hombre se ve forzado por su razón a desempeñarla como si fuera por orden de otra persona, ya que sin esta 
distinción, el hombre que intenta juzgarse a sí mismo cae en contradicción por ser al mismo tiempo juez y acusado. El hombre debe imaginar, por lo tanto, a otro como juez de sus acciones. Se trata de una persona ideal «que tiene que conocer los corazones, porque el tribunal se establece en el interior del hombre» y a la vez una persona «que obliga siempre» (Kant, 2002c; Ak. VI. 439). Este último requisito lleva a Kant a suponer la existencia de Dios en cuanto ser todopoderoso capaz de proporcionar a sus leyes el efecto que corresponde y a considerar a la conciencia moral como «el principio subjetivo de la responsabilidad de los propios actos ante Dios» (Ibíd.).

Vemos que Kant ha descrito con la ayuda de la imagen del tribunal interior cómo funciona la relación que el hombre tiene con su conciencia. El recurso a dicho tribunal nos lleva a profundizar en el rol mediador que Kant le atribuye a la conciencia moral, lo cual nos permitirá referirnos finalmente a la "presión normativa» que ejerce la conciencias moral sobre nosotros.

\section{El rol mediador de la conciencia moral: ¿qué significa actuar en conciencia?}

Después de esta exposición de la fenomenología kantiana de la conciencia moral debemos preguntarnos: ¿en qué consiste el rol mediador de la conciencia moral? En primer lugar, hay que señalar que Kant se aparta aquí de dos posiciones posibles. Una primera posición consistiría en defender una aplicación silogística de las leyes morales; así, por ejemplo, el paso desde la norma general de «no mentir» a evitar mentirle a un enfermo que pregunta por su posible recuperación, no requeriría más que razonar de la siguiente manera: (a) no se debe mentir, (b) decirle a Pedro que se va a mejorar sabiendo que no será así cuenta como mentira, por lo tanto, (c) no debo decirle a Pedro que mejorará de su enfermedad. Una segunda posición consistiría en darle a la ley moral el carácter de principio general que debe orientar la acción, pero que admitiría excepciones en consideración a las circunstancias particulares. La postura de Kant pasa, en cambio, por la exigencia copulativa de dos requisitos que, a primera vista, parecen incompatibles: el actuar en conciencia (1) implica necesariamente una mediación de la facultad del juicio entre la norma y el caso concreto (el juicio del tribunal interno), y (2) en la aplicación de las leyes prácticas nunca están permitidas las excepciones. Cualquier juicio de la conciencia que concluyera que «en este caso concreto debe hacerse una excepción a la ley moral» sería un error. Esto podría llevarnos al paradójico caso en el cual un sujeto acepte 
en teoría la doctrina kantiana de la imposibilidad moral de hacer excepciones a las leyes morales y al mismo su conciencia le señale que en el caso X debe hacer una excepción. Frente a esta paradoja, que encuentra su raíz tanto en el tipo de universalidad que Kant le atribuye a las leyes prácticas como en la concepción de una armonía prestablecida de deberes morales, la única respuesta que podemos encontrar en la «Doctrina de la Virtud» es la siguiente: Kant, enfrentado a la alternativa de cumplir una norma en contra del juicio de la propia conciencia moral o actuar en conciencia contra la norma moral, preferirá la segunda opción. En este sentido, afirma el filósofo: «Cuando alguien es consciente de haber actuado según la conciencia moral, no se le puede exigir nada más en lo que concierne a la culpa o a la inocencia» (Kant, 2002c; Ak. VI. 401). Esta respuesta es consecuente con la gran importancia que Kant le da en toda su obra a la recta intención moral al momento de actuar. La exigencia moral absoluta de actuar en conciencia se enmarca además en el contexto de la autonomía moral, la cual implica a su vez que todas las decisiones morales que un agente adopte deben contar como sus decisiones personales e indelegables. Pero, ¿no representa la respuesta de Kant un reconocimiento tácito del fracaso de la conciencia moral en el ejercicio de su rol mediador? ¿Qué significa, entonces, para Kant, el «actuar en conciencia»?

Con el fin de responder a estas preguntas, volvamos a la paradoja planteada proponiendo un ejemplo. Pedro sabe que su amigo Juan cometió un acto de infidelidad en contra de su mujer, María, del cual se arrepiente. Pedro ha prometido guardar el secreto, sabiendo además que si María se entera, abandonará a Juan, provocando un doloroso quiebre familiar que afectará además a los hijos de ambos. Si María interroga a Pedro, él podría (a) decirle la verdad a María, rompiendo su promesa y poniendo en riesgo a la familia de su amigo, o (b) mentir a María, desobedeciendo así la ley moral que prohíbe mentir. De acuerdo a la aplicación que Kant mismo hace de sus principios morales (cfr. Kant, 2002c; Ak. VI: 429-431; Ak. VIII: 423-427) la alternativa (b) siempre es inmoral, pero, por otra parte, Pedro tiene la obligación de cumplir sus promesas y de actuar siempre en conciencia. ¿Cómo solucionar esta paradoja?

Más que un fracaso de la moral kantiana, veo en esta paradoja un descubrimiento de los límites de las normas morales universales. Veo además en el mandato que ordena actuar en conciencia la única vía posible de solución al problema de la aplicación práctica de las normas morales en casos difíciles. Para entender esto es necesario analizar varios puntos. En primer lugar, todo sistema de normas universales se enfrenta al problema de la aplicación de estas normas a los casos particulares. En 
el caso del derecho, el mismo Kant señala a propósito de la equidad casos en los cuales la aplicación estricta de las normas jurídicas lleva a una injusticia, como por ejemplo, en el caso de un sirviente a quien se le paga su remuneración anual en moneda fuertemente devaluada. El apotegma de la equidad, señala Kant en relación a este caso, dice que «el derecho más estricto constituye la mayor injusticia». Sin embargo, agrega, «este daño no puede remediarse por el camino jurídico, aunque afecte a una exigencia jurídica, porque esta pertenece al tribunal de la conciencia (fórum poli) mientras que toda cuestión jurídica ha de llevarse ante el derecho civil (fórum soli)» (Kant, 2002c; Ak. VI. 235). En segundo lugar, se debe destacar que decir «yo actúo en conciencia» no resulta pertinente en cualquier circunstancia. Resultaría extraño, por ejemplo, que un profesor dijera a sus alumnos «he decidido en conciencia dictar mis clases y corregir las pruebas» o que un juez dijera «he decidido actuar en conciencia y fallar las causas». Por el contrario, el recurso a la conciencia es relevante precisamente en aquellos casos en que la solución al problema no es evidente y más aún, en aquellos casos en los cuales la persona decide, atendiendo a las especiales circunstancias que rodean el caso, no obedecer una norma de carácter general. Actuar en conciencia consiste entonces en tomar decisiones de acuerdo al propio criterio y asumir la responsabilidad por ellas, sabiendo que estas decisiones pueden no ser comprendidas o incluso pueden sernos imputadas en el caso en el que transgredan las normas morales generales. Esto nos lleva a un tercer punto: el actuar en conciencia implica asumir el riesgo de equivocarse. Las situaciones que exigen el actuar en conciencia son precisamente aquellas en las cuales las normas morales generales se revelan como insuficientes y hay al menos dos cursos de acción que podrían ser racionalmente justificados. En el ejemplo planteado, Pedro podría justificar tanto la acción de decir a María la verdad acerca de la infidelidad de Juan, amparándose en el deber absoluto de «no mentin», como también podría justificar el ocultar dicha información a María, amparándose en la máxima de cumplir las promesas y de no perjudicar la estabilidad de las familias. Pedro se encuentra evidentemente ante un grave conflicto de deberes morales.

El último punto señalado resulta, sin embargo, a primera vista inconciliable con la moral kantiana, ya que Kant dice rechazar expresamente la posibilidad de un auténtico «conflicto de deberes». Todo conflicto de deberes sería aparente, ya que dado que deber y obligación son conceptos «que expresan la necesidad objetiva práctica de determinadas acciones, y puesto que dos reglas opuestas entre sí no pueden ser a la vez necesarias, sino que cuando es deber obrar atendiendo a una, obrar siguiendo a la otra no sólo no es deber alguno, 
sino incluso contrario al deber: es totalmente impensable una colisión de deberes y obligaciones (obligationes non collidatur)» (Kant, 2002c; Ak. VI. 224). En segundo lugar, porque Kant, como ya hemos explicado, señala que las leyes prácticas nunca admiten una excepción (cfr. Kant, 2002a; Ak. IV: 389, 421, 424). A la luz de estos pasajes parece que ni siquiera tendría sentido intentar solucionar el problema del conflicto de deberes, ya que Kant niega que este problema exista. Por otro lado, sin embargo, pertenece también a la obra de Kant el pasaje ya citado acerca de la equidad, que remite expresamente al «tribunal de la conciencia» y también lo dicho en relación a la conciencia moral: «Cuando alguien es consciente de haber actuado según la conciencia moral, no se le puede exigir nada más en lo que concierne a la culpa o a la inocencia» (Kant, 2002c; Ak. VI. 401). Resumiendo el problema, Kant afirma tanto que «no puede haber conflicto de deberes morales» como «se debe actuar siempre en conciencia». La clave que permite compatibilizar estas dos tesis radica, a mi juicio, en lo siguiente: afirmar que no puede existir un conflicto de deberes no implica afirmar que siempre podamos saber con certeza cuál es el verdadero deber y cuál es el falso deber. Si esto no fuera así, es decir, si Kant hubiera pensado que la solución a los dilemas morales era siempre clara y nítida, ¿para qué se hubiera molestado en analizar en desarrollar una detallada fenomenología de la conciencia moral? ¿Para qué hablar siquiera de la conciencia moral? Kant ha visto que hay un ámbito de indeterminación o de duda en la vida moral que no obedece finalmente a un defecto de las leyes morales, sino más bien a la finitud y falibilidad inherentes a la razón humana y a la infinita variedad de circunstancias con las cuales podemos vernos enfrentados a lo largo de nuestra vida. A partir de lo anterior se revela la vital importancia que cumple la conciencia moral en el pensamiento de Kant. Sin este rol la vida moral no sería posible, no sólo por la existencia de paradojas morales, sino también porque en una ética que privilegia la buena voluntad por sobre las consecuencias de las acciones debe ser el propio sujeto moral quien tome las decisiones morales y asuma la responsabilidad por ellas. Así también Kant, al privilegiar la mediación de la conciencia moral por sobre una aplicación mecánica de las leyes morales, reconoce implícitamente la dificultad propia de las decisiones morales y renuncia a juzgar moralmente a quienes actúan de acuerdo a su conciencia. Un juicio moral definitivo acerca de nuestras acciones, piensa Kant, sólo podría hacerlo Dios (cfr. Kant, 2002c; Ak. VI. 439). 


\section{Conciencia moral y normatividad}

¿Ilumina la reflexión kantiana acerca de la conciencia moral el problema de la normatividad de las leyes morales? Para saberlo, debemos volver al punto de partida. La pregunta central que debíamos responder era la siguiente: ¿es la fenomenología de la conciencia moral propuesta por Kant un testimonio suficiente de la normatividad de las leyes prácticas? En otras palabras: ¿ejercen las leyes prácticas una presión normativa sobre nosotros a través de la conciencia moral?

Sostengo que la respuesta a esta pregunta es «Síi». Es claro que experimentamos la conciencia moral como un tribunal interior. La normatividad de las leyes prácticas es confirmada a través del fenómeno que denominamos «actuar en conciencia». Dicho fenómeno no consiste en dictar normas morales, sino en aplicar las normas morales ya existentes a las situaciones concretas. La conciencia moral no nos habla en términos hipotéticos («si quieres obtener $\mathrm{X}$, debes realizar la acción $\mathrm{Y} »)$, sino en términos categóricos: «debes hacer $\mathrm{X}$ », «no debes hacer $\mathrm{X}$ » $\mathrm{y}$ especialmente "no debiste haber hecho X». La conciencia no nos reprocha nuestras acciones en términos prudenciales o utilitarios, sino en términos morales, es decir, en términos categóricos. Cuando mi conciencia me manda tener paciencia con mis hijos, trabajar más concentradamente o decir la verdad, no lo hace bajo ninguna condición. Los razonamientos hipotéticos, como por ejemplo, «si quieres ser un buen padre, debes ser paciente» o «si quieres tener éxito, debes trabajar concentradamente», no son propios de la conciencia moral, sino más bien razonamientos prudenciales. En este punto se inserta la reflexión propuesta más arriba acerca del rol mediador de la conciencia. No tiene sentido, decía antes, invocar el rol de la conciencia a propósito del cumplimiento de deberes que no admiten mayor discusión, como el deber del profesor de hacer sus clases o del juez de dictar sentencias, ni menos en relación a decisiones triviales. Tiene sentido decir «estoy actuando en conciencia» cuando se trata de decisiones morales complejas, en las cuales se presentan varios cursos de acción que pueden ser justificados racionalmente. Precisamente en esta clase de decisiones experimentamos con mayor fuerza la presión normativa que la conciencia moral ejerce sobre nosotros: sentimos que en estas decisiones que debemos tomar aquí y ahora y cuyo resultado es incierto se juega nuestro sentido de justicia y nuestra dignidad moral. Aquí se revela además con mucha claridad el rol mediador de la conciencia moral. Mi conciencia me señala, por ejemplo, que el deber de buscar la felicidad ajena pasa en este momento, aquí y ahora, por intentar aconsejar a esa persona que me cuenta un grave problema personal, o que el deber de no 
mentir pasa, aquí y ahora, por citar rigurosamente los libros que me han servido de apoyo para escribir este trabajo. La conciencia moral, sin embargo, como Kant ha visto correctamente, no está libre de errores. Sin embargo, es mi propia dignidad quien finalmente me exige que sea yo mismo quien tome mis propias decisiones morales y me responsabilice por ellas, sin rehuir el peso de mi decisión amparándome en la obediencia ciega a las normas morales generales. Para que el cumplimiento de estas normas morales realmente signifique actuar moralmente, ellas deben ser mis normas, es decir, deben pasar por mi conciencia moral ${ }^{7}$.

\section{Conclusión}

Kant ha visto mejor que nadie un aspecto central de las obligaciones morales: su carácter absoluto, es decir, que las obligaciones morales no están sujetas a condición alguna. El objetivo de este trabajo ha sido mostrar de qué manera este carácter absoluto de los deberes morales, lejos de ser una hipótesis meramente teórica, es confirmado a través de una experiencia que todo hombre puede reivindicar para sí: aquello que llamamos «actuar en conciencia». A través de la conciencia moral

$7 \quad$ El planteamiento que he desarrollado en estas páginas a partir del pensamiento de Kant no está exento de problemas. Una importante objeción apunta a que la conciencia moral no actúa de la misma manera ni en el mismo grado en todas las personas. Se podría decir entonces que para que la conciencia moral opere de la forma arriba descrita serían necesarias ciertas condiciones, entre ellas, una adecuada formación moral y, en especial, el interés por actuar moralmente. ¿Qué pasaría entonces en el caso de que una persona no tuviera el menor interés en ser moral y declarar ser, por ejemplo, egoísta o derechamente amoral? A pesar de que en la moral kantiana no hay lugar para la amoralidad o el escepticismo moral respecto del propio obrar (cfr. Kant, 2002a; Ak. IV: 403-404) es necesario hacerse cargo de esta objeción. Las leyes prácticas son leyes morales de la razón, es decir, son formuladas a través de la aplicación del principio de moralidad, el imperativo categórico. Negar la normatividad de las leyes prácticas significa abandonar el espacio común de la razón. Debemos aceptar que la normatividad de la razón, que tiene lugar a través de la acción de la conciencia moral, es imperfecta, y que la razón de esta imperfección radica, en última instancia, en la libertad humana. A pesar de que debemos actuar según las normas morales, es claro que también podemos actuar contra ellas. Quien decide actuar en contra de la voz de la razón manifestada en la conciencia moral debe someterse, sin embargo, a la normatividad propia del ordenamiento jurídico, es decir, a las sanciones externas, un sistema normativo al que Kant atribuye un alcance más limitado, ya que sólo se refiere a las acciones en cuanto hechos que afectan el ejercicio del arbitrio de otros, pero al que atribuye una normatividad necesariamente respaldada por sanciones. Entre el concepto de derecho y la facultad de coaccionar, así Kant en la Doctrina del Derecho (Rechtslehre), existe una relación analítica (Kant, 2002c; Ak. VI. 237). 
experimentamos la "presión normativa» que ejercen sobre nosotros las leyes morales. Una presión normativa que no proviene del temor a las sanciones, sino de nuestra propia razón.

\section{REFERENCIAS}

-Bilbeny, N. (1994) Kanty el tribunal de la conciencia. Barcelona: Gedisa.

-González, A. M. (1999), El Faktum de la razón. La solución kantiana al problema de la fundamentación de la moral. Pamplona: Eunsa.

-González Vallejos, M. (2010). El concepto de leyes prácticas en la ética kantiana. Revista de Filosofía, 66, 107-126.

-González Vallejos, M. (2012). Die Wende im Begriff der praktischen Gesetze bei Kant. Saarbrücken: Südwestdeutscher Verlag für Hochschulschrifte.

-Henrich, D. (1998). The Deduction of the Moral Law. The Reason for the Obscurity of the Final Section of Kant's Groundwork of the Metaphysics of Morals. En P. Guyer (Ed.), Kant's Groundwork of the Metaphysics of Morals. Critical Essays (págs. 303-341). Boston Mass. and Oxford: Rowman \& Littlefield.

-Höffe, O. (2002). Einführung in der Kritik der praktischen Vernunft. En O. Höffe (Ed.), Immanuel Kant. Kritik der praktischen Vernunft. Berlin: Akademie Verlag.

-Kant, I. (1902ss). Akademie Ausgabe [Ak]. (Ed. Deutsche Akademie der Wissenschaften). Berlin (bisher erschienen: 29 Bde. in vier Abt.): De Gruyter Verlag.

-Kant, I. (2004). Vorlesung zur Moralphilosophie. (W. Stark, Ed.). Berlin/New York: De Gruyter Verlag.

-Kant, I. (1986). En torno al tópico: “tal vez eso sea correcto en teoría, pero no sirve para la práctica”. En I. Kant, Teoría y Práctica (F. Pérez López \& R. Rodríguez Aramayo, Trads.) Madrid: Tecnos.

-Kant, I. (2002a). Fundamentación para la Metafisica de las Costumbres (R. Aramayo, Trad.). Madrid: Alianza.

-Kant, I. (2002b). Crítica de la razón práctica (R. Aramayo, Trad.). Madrid: Alianza. -Kant, I. (2002c). Metafisica de las costumbres (A. Cortina y J. Conill, Trads.). Madrid: Tecnos.

-Kant (2007). Crítica del Juicio (M. García Morente, Trad.). Madrid: EspasaCalpe.

-Korsgaard, C. (1996). Creating the Kingdom of Ends. Cambridge: Cambridge University Press.

-Stemmer, P. (2009). Die Konstitution der normativen Wirklichkeit. En R. Forst \& K. Günther (Eds.), Die Herausbildung normativer Ordnungen. Interdisziplinäre Perspektiven (págs. 57-68). Frankfurt: Campus.

-Schônecker, D. \& Wood, A. (2002). Kants "Grundlegung zur Metaphysik der Sitten". Paderborn: Schöningh. 
-Willaschek, M. (1992). Praktische Vernunft: Handlungstheorie und Moralbegründung bei Kant. Stuttgart: J. B. Metzler.

Sumario: Introducción; 1. El problema de la normatividad de las leyes morales en el contexto de la filosofía moral kantiana; 2. El factum de la razón; 3. Problemas filosóficos asociados al factum de la razón y las normas morales; 4. La conciencia moral; 4.1. La conciencia moral (Gewissen) en la Crítica de la razón práctica; 4.2. La conciencia moral en la «Doctrina de la virtud»; 5. El rol mediador de la conciencia moral: ¿qué significa actuar en conciencia? 6. Conciencia moral y normatividad; Conclusión; Referencias. 